\title{
Short and long-term outcome of 75 or over aged patients admitted to intensive care unit (ICU): a single center, observational study
}

\author{
D Lathyris', M Bogiatzopoulos, A Boutou, F Renta, E Antipa, E Chassou, E Antoniadou \\ From ESICM LIVES 2015 \\ Berlin, Germany. 3-7 October 2015
}

\section{Introduction}

Age is considered an independent risk factor for short and long-term mortality of elderly ICU patients, when very elderly ( $\geq 85$ years) and mid-elderly (75-84 years) populations are compared to young elderly (65-74 years) ones. However, it is not yet clear if this trend remains when very elderly are compared to mid-elderly populations.

\section{Objectives}

a) To compare short (ICU and hospital) and long-term (6-months and 1-year) mortality of mid-elderly to very elderly patients and

b) to evaluate the influence of patients' characteristics on mortality.

\section{Methods}

Single center, retrospective, observational study in an 8-bed adult general ICU (January 2011-June 2014). Patients $\geq 75$ years were divided into two age-groups, $75-84$ and $\geq 85$ years old. Characteristics on ICU admission were recorded. Patients hospitalized $\leq 48$ hours were excluded. ICU, hospital, 6-months and 1-year after hospital discharge mortality were calculated. Univariate analysis for categorical variables was performed using Pearson's x2 or Fisher test and Student t-test for continuous data. Multivariate analysis of the time to ICU mortality was calculated using Cox regression model and for hospital, 6-months and 1-year mortality using logistic regression analysis. $\mathrm{P}$ value $<0.05$ was considered significant.

\section{Results}

244 patients were included, 195 in the $75-84$ and 49 in the $\geq 85$ years group. Mortality rates for the two groups were: ICU, 74/195 (37.9\%) vs. $24 / 49(49 \%)(\mathrm{p}=0.08)$, hospital, $23 / 121(19 \%)$ vs. $5 / 25(20 \%)(\mathrm{p}=0.90)$, 6-months, $15 / 95(17 \%)$ vs. $4 / 20(20 \%)(\mathrm{p}=0.74)$ and 1 -year, $22 / 80(27.5 \%)$ vs. $7 / 16(20 \%)(\mathrm{p}=0.19)$, respectively. In multivariable analysis, patients with malignancy as reason for ICU admission had increased ICU mortality risk (HR:1.45; CI 95\%, 1.02-2.05; $\mathrm{p}=0.03$ ). Patients with higher APACHE II score on ICU admission had more important 1-year mortality risk (OR:1.09; CI 95\%, $1.016-1.16 ; \mathrm{p}=0.015)$.

\section{Conclusions}

More than one third of our ICU patients were mid- or very elderly. No difference was observed between the two age-groups considering short or long-term mortality. Malignancy as a reason for ICU admission and APACHE II score negatively influenced the ICU and 1-year mortality, respectively.

\section{Published: 1 October 2015}

\section{References}

1. Fuchs L, Novack V, McLennan S, Celi LA, Baufield Y, Park S, et al: Trends in severity of illness on ICU admission and mortality among the elderly. PLoS One 2014, 9(4):e93234.

2. Fuchs L, Chronaki CE, Park S, Novack V, Baumfield Y, Scott D, et al: ICU admission characteristics and mortality rates among elderly and very elderly patients. Intensive Care Med 2012, 38(10):1654-1661.

\section{doi:10.1186/2197-425X-3-S1-A528}

Cite this article as: Lathyris et al:: Short and long-term outcome of 75 or over aged patients admitted to intensive care unit (ICU): a single center, observational study. Intensive Care Medicine Experimental 2015 3(Suppl 1):A528. 